\title{
Juan Antonio González Iglesias: la recepción clásica en un poeta alejandrino posmoderno
}

\author{
Carlos Mariscal de Gante Centeno \\ Universidad Complutense de Madrid \\ charlie.mariscal@yahoo.es
}

Feliz el que te dé clases particulares y en la brutalidad de tus labios escuche

la frágil hermosura de la rosa rosae

J.A. GONZÁLEZ IGLESIAS

Recibido: 10 de junio de 2015

Aceptado: 20 de septiembre de 2015

\section{RESUMEN}

Este artículo estudia los elementos clásicos presentes en la poesía de Juan Antonio González Iglesias, poeta y latinista salmantino, en sus poemarios publicados hasta el año 2007. Se estudiará la forma tan peculiar que toma la literatura grecolatina en nuestro poeta, ya que en la posmodernidad la herencia clásica se ve abocada a adoptar nuevas formas, estableciendo así un diálogo con la Antigüedad, de la que se recrean selectivamente algunos elementos. Además, podremos comprobar cómo los elementos clásicos conviven con otros, antiguos y modernos, que se mencionarán cuando se unan a los clásicos.

Palabras clave: Juan Antonio González Iglesias. Del lado del amor. Poesía española. Recepción clásica. Neoculturalismo.

Mariscal de Gante Centeno, C., «Juan Antonio González Iglesias: la recepción clásica en un poeta alejandrino posmoderno», Cuad. Fil. Clás. Estud. Lat. 35.2 (2015) 337-361.

\section{Juan Antonio González Iglesias: The classical reception in a postmodern alexandrian poet}

\begin{abstract}
This paper studies the classical elements in the poems of Juan Antonio González Iglesias, a poet and latinist from Salamanca. It will study his poetry books published until 2007. There we will observe the unusual form that greek and latin literature assumes in our poet, as in postmodernity the classical heritage is forced to asume new forms, setting this way a dialogue with the Antiquity. Of this Antiquity he will recreate some elements carefully. The classical reception will also be among other elements, old and modern, that will be mentioned when they join with the classical ones.
\end{abstract}

Keywords: Juan Antonio González Iglesias. Del lado del amor. Spanish poetry. Classical reception. Neoculturalism.

SuMARIO: 1. Introducción bio-bibliográfica. 2. Líneas generales de la poesía y la estética de Juan Antonio González Iglesias. 3. Elementos clásicos en la obra de Juan Antonio González Iglesias. 3.1. La hermosura del héroe (1994). 3.2. Esto es mi cuerpo (1997). 3.3. Un ángulo me basta (2002). 3.4. Selva de fábula (2010). 3.5. Olímpicas (2004). 3.6. Eros es más (2007). 4. Conclusiones. 5. Referencias bibliográfícas. 


\section{INTRODUCCIÓN BIO-BIBLIOGRÁFICA}

Juan Antonio González Iglesias, nacido en Salamanca en 1964, es un poeta y latinista que se ha convertido en un fenómeno literario muy peculiar, suscitando un gran interés en ámbitos muy diversos. Tanto es así que ha dado lugar a ingeniosas definiciones sobre él como «Ovidio con iPod» en (Rodríguez 2007) o sobre su poesía, «entre el gimnasio y la biblioteca» (Villena 2007), esta última reproduciendo versos suyos. Y es que el latinista, traductor de Catulo (González Iglesias y Fernández Corte 2006), de los Amores de Ovidio (González Iglesias 1993) y del Ars poetica de Horacio (González Iglesias 2012a) es además un excelente poeta y así ha sido reconocido dentro y fuera de nuestras fronteras. Prueba de ello son la obtención del premio Loewe de poesía en 2008, la traducción de su poemario Eros es más al inglés (González Iglesias 2014) y de Esto es mi cuerpo al francés (González Iglesias 2012b) o las recentísimas concesiones del Premio del Tren 2014 Antonio Machado y el XXXVI Premio Ciudad de Melilla también de 2014. Él mismo en una entrevista (Ruano 2014) se reconoce fundamentalmente como poeta y considera un privilegio su trabajo como profesor de latín en la Universidad de Salamanca: «Pienso que soy un poeta que enseña la obra de algunos grandes poetas, como Horacio, Catulo o Virgilio. Enseño también un idioma que ya es puramente poético, como el latín».

Las obras que estudiaremos en este trabajo son los poemarios publicados por González Iglesias hasta 2007: La hermosura del héroe (1994), premio Vicente Núñez en 1993; Esto es mi cuerpo (1997), accesit del Premio Gil de Biedma; Un ángulo me basta (2002), Premio Internacional de Poesía Generación del 27; Selva de fábula (1995- 2002); Olímpicas (2005), incluido en la biblioteca del COI en Lausanna, y Eros es más (2007), premio Loewe.

La fusión entre los escritos de autores grecolatinos y la más contemporánea modernidad es algo que preocupa a nuestro poeta también en su faceta de filólogo, reflejando así su preocupación por el papel de los clásicos en medio de la llamada cultura pop en sus publicaciones académicas. Prueba de ello son, por ejemplo sus textos sobre la fortuna de Hor.Carm.3.30 en una irónica escultura de los hermanos Poitier, que crean un monumentum muy particular (González Iglesias 1994), su análisis sobre la pervivencia del imperativo horaciano carpe diem, desde Epicuro y el propio Horacio hasta las latas de la Coca-Cola, pasando por otros escritores y publicistas (González Iglesias 2010c) o el apéndice que incluye en su traducción del Ars poetica, donde aplica los preceptos horacianos, además de a artistas y escritores, a periodistas, tuiteros y blogueros (González Iglesias 2012a, pp.141-174). Las normas de la escritura no han cambiado, aunque sí lo hayan hecho los soportes.

Esta relación contemporánea entre la cultura de masas pop y algunos aspectos de la tradición precedente, fundamentalmente la grecolatina, es algo que González Iglesias declara como constitutivo de su misma forma de entender la poesía, junto con un afán de incorporarse al elenco de grandes poetas que, incluso, el autor desearía que lo leyesen, como afirma en el cuestionario de Cambio de siglo (SánchezMesa 2007, pp. 258-261): 
Y escribo teniendo en mente eso. Sobra decir que pienso en mis contemporáneos y en los que vendrán. Pero un poeta debe escribir en primer lugar para los hombres que le precedieron (por ejemplo, como si Virgilio o Góngora fueran a leerme, porque quizá lo hagan). Una última cuestión relacionada con la identidad: el viejo sueño de la humanitas clásica es el mío: un ser humano libre, respetuoso con los demás, amante de la naturaleza y del arte, consciente de sus límites y defensor de la dignidad humana.

Por eso, piensa González Iglesias que el poeta tiene que ocupar una posición relevante en el mundo. En una conferencia pronunciada en la Fundación Juan March (González Iglesias 2010b, p.28) reconoce la importancia de la implicación del poeta en la sociedad, diciendo: «Debe regir una ley de necesidad: el poeta debe decir aquello que, si no fuera por él, quedaría sin decir. También le incumbe recordar a sus contemporáneos algunas verdades elementales que ya se han dicho». En una entrevista, (Rodríguez 2007), se lamenta de que «teniendo un sistema de enseñanza que permitiría educar a cada ciudadano como un senador romano, añadiendo las nuevas tecnologías, deliberadamente se rebajan los niveles educativos ${ }^{1}$.

\section{LÍNEAS GENERALES DE LA POESÍA Y LA ESTÉTICA DE JUAN ANTO- NIO GONZÁLEZ IGLESIAS}

Luis Antonio de Villena (2007) ha definido de forma perspicaz a nuestro autor, a partir de su escritura: «Salmantino antiguo, pindárico moderno, amante de la flexibilidad, como cuerpo y energía, este refinado filólogo es un absoluto moderno». Y es que en la obra de González Iglesias la tradición grecolatina está presente, junto a otras tantas, como la gongorina, la de la Epistola moral a Fabio de Andrés Fernández de Andrada, Walt Whitman o Ezra Pound. La que nosotros estudiaremos es la de los elementos clásicos, en su convivencia con otros y, también, la peculiar forma que les confiere González Iglesias.

En su poesía se mezclan, como veremos, un importante conocimiento de la Antigüedad grecolatina, de sus poetas, sus filósofos y sus grandes hombres con una atenta lectura de otros poetas, modernos, barrocos o contemporáneos. Se dan en él, como reza nuestro título, la minuciosidad del alejandrino -como ese sutil lector y comentarista de la Antigüedad que conoce a los clásicos, los recrea, los alaba y los enfrenta en sus obras, como guiño para los lectores cultivados, al estilo de un Calímaco o un Apolonio- junto a un hombre profundamente apegado a su tiempo, su realidad y sus aficiones deportivas. De ahí que hayamos querido dejar clara esta doble faceta del poeta desde el título mismo de este trabajo: «un poeta alejandrino posmoderno».

\footnotetext{
${ }^{1}$ Resulta curioso que su pensamiento sobre la acción que la poesía tiene sobre el mundo se haya visto realizado a través de su poema «Canción para pedir más carril bici» (González Iglesias 2010, pp.229-331), pues, a raíz de su reivindicación en forma de poema, el Ayuntamiento de Salamanca procedió a ampliarlo.
} 
Estos elementos clásicos no son imitación ni mera referencia, sino más bien diálogo con la Antigüedad, de la que se toman los géneros, citas e incluso elementos gramaticales que al poeta le sugieren una realidad nueva para sus poemas, otorgándoles un carácter diferente. No hay en él, pues, servilismo. Esta corriente, de fusión de lo antiguo con lo cotidiano y la cultura de masas, entronca con toda una tradición poética que se ha venido dando en España, cuyos primeros representantes fueron algunos de los llamados 'novísimos' por la antología de Castellet, que han tenido múltiples y notables seguidores. Una buena recopilación de ellos y algunos otros poetas es Orfeo XXI, la antología de Conde Parrado y García Rodríguez (2005), donde se recogen los poemas de nada menos que 105 poetas españoles, en la línea abierta por estos 'novísimos'.

Sobre este asunto, concretamente sobre la obra de los poetas que publican en torno al cambio de siglo, Sánchez-Mesa (2007, pp.29-61) establece una serie características generales, comunes a todos ellos, que pasamos a enumerar, por lo extenso de su redacción: recuperación de la posibilidad de un sentido de originalidad a tradiciones poéticas accesibles (fundamental para entender a nuestro poeta), un afán de trascendencia, un despojamiento formal y tendencia al fragmento (veremos que ésta es muy importante en composiciones breves), la conciencia del lenguaje, un menor confesionalismo en los poemas, un escéptico nihilismo, una tendencia a la denuncia socio-política, un culturalismo poroso a otras realidades (algo en lo que destaca también González Iglesias), una creciente presencia de la imagen, una indagación en la construcción individual y una conciencia teórico-poética menos polarizada (fundamentalmente, en torno a la polémica de la poesía de la experiencia y la poesía social).

Villena (2010, p.26) en una antología poética de la llamada Generación del 2000 dice sobre González Iglesias:

Es un poeta que opta de manera muy marcada por el seguimiento de una poética muy apegada a la más rigurosa "tradición clásica". Por ello en él aparece la reflexión, la imagen de cuño culturalista, acendradamente grecolatina, y la puesta en servicio de todos estos elementos para una reflexión hímnica sobre la vida plenamente contemporánea. Su opción resulta novedosa, sin dejar de ser muy clásica. El lector percibirá de qué modo tan sutil el andamiaje clasicista se convierte, en un verso muy limpio, muy moderno, en contemporaneidad absoluta.

Esta afirmación constituye una apuesta estética en sí misma, pues en nuestras letras contemporáneas no son canónicas las referencias al legado cultural de Grecia y Roma, como en los siglos precedentes, aunque, como atestigua Orfeo XXI, no es nada desdeñable. Sobre esta apuesta estética, nos dice García Rodríguez (2005):

Por el contrario, la aparición de figuras mitológicas o elementos procedentes de la tradición clásica en un poema contemporáneo, aunque ni mucho menos imposible y ni siquiera exótica, constituye simplemente una más de las múltiples opciones estéticas que, dentro de un abanico a priori desjerarquizado, se le ofrecen al poeta actual (...) Con todo, no son, ni mucho menos, escasos los poemas contemporáneos en los que deli- 
beradamente se acude a elementos de la cultura grecolatina (desde personajes hasta géneros literarios, pasando por motivos, estructuras formales, expresiones verbales, etc.).

Por último, es muy significativo, en lo que respecta a la destreza poética de González Iglesias, cómo en sus versos tienen cabida los más clasicistas, herederos del castellano del Renacimiento y el Barroco, en «Selva de fábula» (González Iglesias 2010a, pp.205-207) junto al lenguaje propio de la publicidad de nuestra posmoderna sociedad mercantil, con eslóganes como «Champú johnsons especial para niños» (González Iglesias 2010a, p.28 ), «Ya.com me ofrece megas ilimitados» (González Iglesias 2010a, p.193), obteniendo de ellos, incluso, una máxima poética propia, alterando el orden de un eslogan de la colonia Hugo Boss: «Don't innovate. Imitate» (González Iglesias 2010a, p.321).

\section{ELEMENTOS CLÁSICOS EN LA OBRA DE JUAN ANTONIO GONZÁLEZ IGLESIAS}

El desarrollo ulterior de este trabajo va a consistir en un comentario de aquellos poemas de González Iglesias que nos puedan presentar una recepción clásica en sus versos. El orden de dicho análisis seguirá, cronológicamente, el de publicación de los poemarios de los que se ocupa este trabajo: La hermosura del héroe, Esto es mi cuerpo, Un ángulo me basta, Selva de fábula, Olímpicas y Eros es más.

Antes de comenzar nuestro análisis de los poemas concretos, creemos pertinente presentar las cuatro formas que, al menos, adopta el imaginario clásico en la poesía de González Iglesias: una primera consistente en nombrar los poemas o introducirlos con referencias a textos antiguos que Genette $(1989$, p.12) denomina paratextos y que en principio no tienen conexión con el objeto del poema, que trata un asunto más cercano a nuestro tiempo, con lo que el poeta reta al lector a descubrir por qué y cómo le ha suscitado el poema dicha referencia, como sucede en «Oda III, 4. Homenaje a Horacio» (González Iglesias 2010a, pp.73-74) con los nacimientos de Horacio y de un héroe anónimo o en «Del lado del amor duerme mi cuerpo» (González Iglesias 2010a, pp.65-66), con la formación del futuro ciudadano-amante; una segunda sería propiamente el recurso a versos de poetas antiguos o citas de otros géneros literarios, como sucede en «Olímpica primera» (González Iglesias 2010a, pp.23-26) con Píndaro y el agua, sentencias de filósofos como en «You light up my life» (González Iglesias 2010a, p.280) con Aristóteles o rehaciendo el famoso hexámetro de Virgilio en «La canción del verano suena más que la Eneida» (González Iglesias 2010a, p.70), en los que el poeta encuentra un soporte para su composición y un nuevo sentido a una vieja cita.

Una tercera podríamos decir que es el uso de personajes en varios de sus poemas, con atributos que recuerdan en algo a textos clásicos, como referentes por su vida y no tanto por su obra, como los anónimos héroes de «Catálogo homérico» (González Iglesias 2010a, pp.38-39) e, incluso, los emperadores Adriano en «El reinado de 
Adriano» (González Iglesias 2010a, pp.307-308) y Marco Aurelio en «Correspondencia» (González Iglesias 2010a, p.300); y, finalmente, un uso importante y peculiar es el de la lengua latina y su aprendizaje como recurso estético, por ejemplo con el bello joven que recita la primera declinación en «Bollycao boy» (González Iglesias 2010a, p.35) o las cartas, y sus fórmulas de cortesía latinas, entre Frontón y Marco Aurelio en «Correspondencia» (González Iglesias 2010a, p.300), que dejan ver un pensamiento de reverencia hacia el maestro. Palabras como selva y ángulo, de fuertes resonancias latinas en sus acepciones de 'bosque' y 'rincón' también nos recuerdan la lengua del Lacio.

\subsection{LA HERMOSURA DEL HÉROE (1994)}

En este punto vamos a iniciar nuestro recorrido por los versos de González Iglesias. La hermosura del héroe es su primer poemario publicado, que, como dice él mismo en su prólogo, es una «celebración del héroe, mediante las formas primigenias de la poesía» (González Iglesias 2010a, p.21). Como reza su propio título, estamos ante una alabanza a las virtudes del héroe, del joven bello, del atleta. El elemento básico del poemario es la contemplación del cuerpo masculino, desde una perspectiva homoerótica, pederasta, en el sentido etimológico de la palabra, del experimentado anciano que admira la juventud y la robustez del muchacho hermoso.

Las formas poéticas tradicionales de la literatura griega sufren dos variaciones fundamentales en la pluma de González Iglesias: un cambio en el objeto que se canta en cada género poético, ya sea la oda, el himno o la épica, en su versión breve de epilion, pues ya no se cantan batallas y grandes competiciones entre héroes y reyes, sino que se cambia el combate militar por el de los amantes en el lecho y los grandes héroes de rancio abolengo son ahora atletas, anónimos o reconocidos, como sucede con David Cal o Martín López Zubero; el otro cambio es el del carácter mismo de los vencedores en las competiciones atléticas. Pasamos de unos vencedores concebidos como héroes, con unas dotes sobrehumanas y cercanas a los dioses, a unos esforzados deportistas, identificables ya como ídolos de masas que han ido labrándose su potencial físico.

El primer poema de esta obra, «Olímpica primera. Nadador», abre también la serie de odas olímpicas que veremos recogidas en una obra más tardía y está dedicado a Martín López Zubero, un galardonado atleta hispano-estadounidense. En él está clara la referencia a Píndaro, ya que el poema comienza recordando la aseveración del poeta griego «óp la partícula « $\mu \varepsilon \dot{v}\rangle$, por su escaso vacío semántico, con lo que se consigue una mayor sentenciosidad en el verso. Después, el poema narra una de sus competiciones, en medio de la cual encontramos claros ecos de elementos griegos, homéricos y pindáricos (González Iglesias 2010a, p.25):

Ceremonioso ante el anciano inclinas

la preciosa cabeza de recluta,

de potro que después de la carrera 
recibe la áurea brida en mansedumbre.

Oro te muerden en tu freno duro.

Oro relumbra entre los pectorales.

Oro en custodia sobre la loriga

palpitante y suave de este héroe.

En los versos finales se repite en anáfora la palabra 'oro', que modernamente representa el primer puesto de las competiciones atléticas y que está muy presente en Píndaro como símbolo de excelencia, como afirman Bádenas y Bernabé (2002, p.25). También, encontramos la loriga del héroe, sobre la que se coloca el atleta la medalla dorada, reminiscencia del equipo del que iba pertrechado el héroe griego. Además, en los últimos versos califica al atleta como «príncipe oceánida» (González Iglesias 2010a, p.26), con un epíteto de fuerte resonancia homérica. Todo ello conforma el ambiente propio de los epinicios de Píndaro, en el que González Iglesias crea su moderna oda a Martín López Zubero. Píndaro, por tanto, está latiendo en el texto, a pesar de que la descripción de la competición tiene un inequívoco carácter contemporáneo.

«Bollycao Boy» (González Iglesias 2010a, p.35) versa sobre un joven deportista, quien, tras salir del polideportivo (sucedáneo de los gimnasia griegos), rebusca en la mochila para encontrar su bollycao, alimento con el que han crecido los jóvenes españoles del último medio siglo. Esta búsqueda acaba siendo un canto a la belleza del muchacho, recitando la primera declinación. El latín se convierte en un generador de atracción erótica:

El caos de tu mochila ¿quién lo nombra?
canicas camisetas cromos cartas
gruesos rotuladores fluorescentes
cordones la revista dos cartuchos
de combativos juegos informáticos
En cuidadoso estuche cual secreto
los preciosos cristales
que cubren tu miopía maravillosa
el slip fabuloso de repuesto
tal vez ya tu primer preservativo
publicitario. Al fin el bollycao
puesto por mamá, joven y atractiva
el bonobús las llaves la toalla
el libro de latín de segundo de bup...
Feliz el que te dé clases particulares
y en la brutalidad de tus labios escuche
la frágil hermosura de la rosa rosae

En este poema tanto el libro de latín, que cierra la lista de objetos de la mochila, como el joven que recita la declinación son la conclusión y clímax. El aprendizaje del latín es aquí motivo de embelesamiento del profesor ante la belleza de la recita- 
ción de su alumno ${ }^{2}$. Hay otros momentos de la literatura del siglo XX en que el latín también es un recurso poético, como el poema de Rafael Alberti «Noticiario de un colegial melancólico», comentado por García Jurado (2006, pp.19-20), en el que el poeta declina en sus versos la palabra española 'nieve' o de Gerardo Diego y su juego de palabras con las formas verbales del verbo tango en aliteración en «Púnica Dido», comentado por Cristóbal (1997, p.38): «Tetigi tingitania que te tango». Por su parte, la última estrofa, naturalmente, nos lleva hacia Horacio en Epod.2, que comienza con

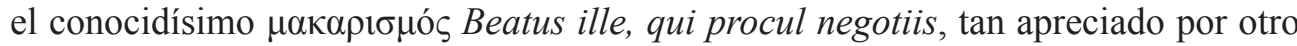
gran poeta, Fray Luis de León, muy productivo en los versos de González Iglesias, como señala en su artículo Ponce (2014, p.V).

Otro de los poemas de esta obra que merecen nuestra atención es «California dream» (González Iglesias 2010a, p.37). Todo él es un nuevo canto a un joven. En este caso la hermosura de su cuerpo se contrapone al viento que le golpea en la frente, lo cual le recuerda al poeta la brevedad del tiempo en que éste será joven y hermoso y que le llegará, algún día, su final: «Que algún día seremos sombra y nada». Con este pasaje González Iglesias se introduce en la tradición de un tópico literario, que parte de la Biblia, Homero y Píndaro, a través de otros autores clásicos, pasando en España por Góngora, con diferentes versiones, que tiene como elementos la tierra, el polvo, la sombra y la nada como metáforas de la muerte, cuya génesis ha estudiado Laguna (1999, pp.197-213).

Otro caso interesante es el de «Catálogo homérico» (González Iglesias 2010a, pp.38-39). En él, nuevamente, se altera un elemento de la literatura clásica, en este caso el catálogo de las naves de Hom.Il.2, y, nuevamente también, nos muestra a un héroe muy distinto al tradicional, que en este caso, además, se diluye en muchos otros. Son más bien las características y excelencias del cuerpo las que aquí se cantan, pues el catálogo antiguo se le queda corto al poeta para lo que quiere expresar: la belleza masculina universal:

Lo cierto es que no hay

catálogo ni poeta

alejandrino cuya lengua

baste para nombrar la serie de los héroes.

Es el alumno que descentra el mundo

incapaz de domar

el gemelo fulgor de sus pupilas

los dos que en los recuerdos del verano

comen un helado, es

Jonathan en Estocolmo

o Fernando en Madrid,

\footnotetext{
${ }^{2}$ Esta referencia a la recitación de la primera declinación latina puede tener detrás también la canción Rosa de Jacques Brel, cuyo videoclip (https:/www.youtube.com/watch?v=v6rLLE48RL0), además, tiene lugar en un aula. Una nueva fusión del imaginario clásico con el contemporáneo, en un espacio académico y con una temática amorosa como la del poema.
} 
Gilbert en Avignon,

Sebastián en cada uno de sus actos,

soy yo mismo en Verona,

delante de una casa donde dice

éste es el discípulo del amor.

Este uso alternativo del catálogo antiguo se remonta a Walt Whitman y sus cantos democráticos en Hojas de hierba, sobre los que Martín de Riquer y José María Valverde (2010a, p.395), casi proféticamente, afirman: «La lírica del catálogo anunciaba un nuevo sentido que sólo el siglo XX hallaría en la poesía». Un género antiguo, que emplea nuestro poeta, con una intención muy diferente a la original, pero mostrando su deuda con el texto homérico, desde el mismo título.

«Alcibíades» (González Iglesias 2010a, p.43) es un breve poema en el que González Iglesias se vale del joven militar y miembro del círculo socrático. En este poema extraño, que es una suerte de ficha o curriculum del joven griego, la influencia clásica no va más allá del objeto y el título del mismo. Un género poético nuevo y alternativo, al que se suma un personaje de la Grecia clásica:

Del griego А $\lambda \kappa \imath \beta \iota \alpha ́ \delta \varepsilon \varsigma$

Nombre propio masculino.

General ateniense

nieto de Pericles y discípulo de Sócrates

Fue célebre por las felices disposiciones

que la naturaleza le había concedido

y por sus alternativas

de suerte y de desgracia.

«Fragmento épico» (González Iglesias 2010a, pp.47-48) nos relata el regreso de unos jóvenes tras jugar un partido de baloncesto que, al llegar a su habitación, acabarán por atraerse en medio de la noche y librar el combate del amor sobre el lecho. Es notable para nuestro estudio, además de que sea un nuevo canto a un amor homoerótico, el hecho de que este poema se titule «Fragmento épico», es decir, un epilion (un pequeño epos, que es a lo que, en lengua española, se refiere González Iglesias). Un género que desde su mismo nacimiento, con Calímaco y Teócrito, ha contado historias de amor. El imaginario griego encuadra el combate:

(...) Se comprueban, se muerden

conocen los calibres gemelos, se entrelazan

inmortal y mortal, dorios en su desnudo

de púgil y guerrero. El combate desata

simetría de torsos recentísimos, tensa

emisión simultánea de dos constelaciones

(...) Se mezclan dulcemente en la altura, en las proporcionadas cabezas, que descansan

unidas mientras llega el sueño de los héroes. 
Con «Nuevo himno» González Iglesias (2010a, pp.53-54) nos presenta un poema que quiere adoptar el tono solemne y elogioso hacia la divinidad que tenían los himnos griegos, cuyas cumbres se encuentran en los Himnos homéricos y los Himnos de Calímaco. En este caso, sin embargo, el objeto del poema es, nuevamente, un hermoso joven deportista, anónimo en este caso. Ahora el héroe pugna en belleza y forma física, sin que nos importe su linaje, ni siquiera su nombre. Su combate tiene lugar en las noches de amor de los jóvenes deportistas y todos los recursos que la tradición literaria ha ido proporcionando sirven a ese propósito. Este desplazamiento de la divinidad por un joven muchacho, lo justifica González Iglesias en su poema, precisamente en virtud de su hermosura:

No te conocen. Pero yo te canto.

Canto la arborescencia de tus venas,

el trapecio de luz de tu cintura,

canto tu diminuta tonelada,

canto la mies la mina de tu pelo,

la diagonal caliente en la que duermes.

Por último, «Propempticon» (González Iglesias 2010a, p.55) recupera, nueva-

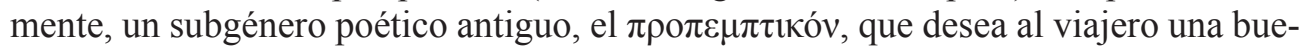
na travesía. En este caso, el poema canta a un joven que ha llegado a la edad adulta. El encargo que el poeta hace al joven es el de ser una suerte de enviado del amor:

Tu tarea es necesaria porque tiene

la posmodernidad que ser futuro.

Ahora te espera

un largo viaje en nombre del amor.

La búsqueda del Grial ha comenzado.

\subsection{ESTO ES MI CUERPO (1997)}

Este poemario retoma el tema del cuerpo atlético masculino de los héroes contemporáneos, que ya hemos tenido oportunidad de leer. En él hay un referente clásico: el poeta latino Horacio. El epicureísmo horaciano y los poemas autobiográficos Carm.3.2 y 3.4.

El primer poema en el que debemos detenernos tiene el título de «Del lado del amor duerme mi cuerpo» (González Iglesias 2010a, p.65-66). Éste comienza con una cita paratextual, que introduce los versos y dice así: «This is a puzzling poem. G. Williams sobre la Oda III 2 de Horacio». El contenido del poema es una declaración firme del poeta que ha cumplido 30 años y que se recuerda feliz con 19. Una especie de recusatio total, de carpe diem actualizado ${ }^{3}$, en el sentido de que invita

\footnotetext{
${ }^{3}$ No en vano, González Iglesias ha rastreado los ecos del carpe diem epicúreo y horaciano, hasta la más reciente modernidad, como hemos dicho supra (González Iglesias 2010c).
} 
al lector aprovechar el momento, sea para el disfrute o para el dolor. Es decir, que para entregarse plenamente a la vida, para 'dormir del lado del amor', es necesario también padecer vaivenes y aprender de ellos. Lo cual responde a una enseñanza horaciana similar, en este caso para la vida del ciuis romanus, al inicio del mencionado Carm.3.2: Angustam amice pauperiem pati/ robustus acri militia puer/ condiscat. El padecimiento está presente en ambos como aprendizaje, en las relaciones eróticas en el caso de González Iglesias y en el ejército en el caso de Carm.3.2, una de las llamadas Odas romanas del Venusino:

He cumplido también sueños y miedos.

Sea también. He pisado

un septiembre de lágrimas, amargo

como frontera atrás, como vendimia

irremediable. Y eso era el dolor

Ahora he comprendido

que es necesario el ciervo, y es necesario el tigre.

Afirmo todo aquello que negué.

Cómo me salvaré sino queriendo.

He tenido al que fui

con 19 años en mis brazos

y lo he visto feliz. He percibido cómo

mi cuerpo transmitía

esa felicidad.

Horacio está presente en otro poema de este libro, en este caso en su título, «Oda III, 4. Homenaje a Horacio» (González Iglesias 2010a, p.73-74). El poema comienza igual que otro que ya hemos comentado supra (González Iglesias 2010a, p.53): «Nadie profetizó tu nacimiento». Todo él es otro himno a un nuevo héroe cuyo nacimiento carece de relevancia y detrás del cual podría esconderse el propio poeta. Los dos nacimientos que narran los poemas son opuestos, pues Horacio en la citada oda nos relata su propio nacimiento con hechos maravillosos, con las musas acudiendo a coronarlo con laurel y protegiéndolo frente a las inclemencias del lugar y el del anónimo héroe de este poema es un modesto alumbramiento. González Iglesias se remonta a la primera sonrisa del héroe y nos dice:

Pero un día ofreciste

tu primera sonrisa tras diez lunas.

Fuiste maravilloso. Te quedaste

dormido y ni las sierpes ni los osos

te atacaron. Estabas

protegido por una

fronda nueva, palomas de parábola

la tejieron.

Los versos anteriores reproducen las palabras del latín horaciano en Carm.3.4.1213: Fronde nou a puerum palumbes/ texere y en 17-21: Vt tuto ab atris corpore uipe- 
ris/ dormirem et ursis, ut premerer sacra/ lauroque collataque myrto,/ non sine dis animosus infans/ uester, Camenae, uester. El misterioso joven de González Iglesias es visitado por las palomas, que lo cubren con esa fronda nueva en su primera sonrisa. A Horacio, por su parte, le sucede lo mismo como seña de protección de las musas, pues en su caso las palomas lo cubrieron con mirto, planta que nace en las orillas, relacionada con Venus, y laurel, galardón que distinguía a los más excelsos poetas. Las palomas visitan a ambos personajes por razones diferentes, con lo que se ofrece una comparación entre el nacimiento solemne de Horacio y el modesto de este héroe anónimo, detrás del que se oculta, a buen seguro, el propio González Iglesias, que se refiere a sí mismo en segunda persona, a la manera de un diálogo ficticio con su yo infantil.

«La canción del verano suena más que la Eneida» (González Iglesias 2010a, p.70) es, quizá, uno de los más interesantes de nuestro poeta salmantino desde el punto de vista de la recepción clásica. Cristóbal (2009) lo considera «una buena muestra de la actual impronta de los poetas romanos». Leámoslo antes de comentarlo:

La canción del verano suena más que la Eneida

y en vano -Cioran dice- busca Occidente una

forma de agonía digna de su pasado.

Pero así están las cosas, y no tienen

vuelta

ni las generaciones ni las hojas

de los hombres.

Tristeza de saber que no regresaremos

a la ternura, la serenidad

al fulgor de Virgilio.

Aquel verano

bailábamos oscuros bajo la noche sola.

Es claro, nos parece, el homenaje que González Iglesias hace aquí a los dos grandes épicos de la antigüedad grecolatina: Homero y Virgilio. Al poeta griego en «pero así están las cosas, y no tienen/ vuelta/ ni las generaciones ni las hojas/ de los hombres», reproduciendo los versos homéricos de Il.6.146-150, momento del encuentro entre Diomedes y Glauco. Este verso lo retomó Virgilio precisamente en el libro sexto de su epopeya, Aen.6.309-310, para comparar esta vez las hojas caídas en otoño con la multitud de almas que se congregan para intentar cruzar el río Aqueronte. El símil ha sido muy utilizado en la literatura antigua posterior y en algunos escritores contemporáneos, cuya pista, a través de la historia y las literaturas europeas, ha seguido Cristóbal (1992). A González Iglesias, por su parte, le vale para intentar no lamentar la pérdida de Virgilio y su sustitución por el pop comercial.

El otro homenaje, éste plenamente virgiliano, está en los dos últimos versos del poema, que rehacen con mucho ingenio el conocido hexámetro ibant obscuri sola sub nocte per umbram de Aen.6.268. La hipálage, en tanto figura literaria, es discutida por algunos literatos. En concreto, con respecto a obscuri y sola, calificando de forma 
inversa a Eneas y la Sibila y la noche, el maestro argentino, Jorge Luis Borges (2011, pp.364-365), afirma: «Solitarios y oscura no han cambiado su lugar en la frase; ambas formas, la habitual y la virgiliana, corresponden con igual precisión a la escena que representan». La melancolía con la que se inicia el poema ha dejado paso a una hermosa y original reelaboración de uno de los versos más conocidos del Mantuano.

«Número 11 de una avenida nueva» (González Iglesias 2010a, p.105) nos presenta a un amante rechazado que persigue a su amado, hasta llegar a su casa. Es en ese momento en el que recupera nuestro poeta el tópico del $\pi \alpha \rho \alpha \kappa \lambda \alpha v \varsigma^{\prime} \theta v \rho o v$, ampliamente desarrollado en las letras griegas y romanas, como señala Ponce (2014, p.IV-V), con el que se presenta al amante que hace noche a la puerta de su amada, amado en este caso:
(...) Para hacer qué, ¿pulsar
todo el cuadro de timbres, como el adolescente que no fui, despertar muchedumbres, y sólo por dejar en tu sueño la señal de mis sueños? ¿O quedarme dormido sobre la dura almohada del umbral que traspasas a diario, esperando que el sol que nacerá pronto me cure y traiga el milagro a mis brazos, tu cuerpo bienungido con este mismo vino que me asedia las sienes?

En este poemario hemos encontrado también algunos ejemplos de citas de autores clásicos como en «Escrito en Morgana» (González Iglesias 2010a, pp.78-79), donde nuestro poeta se refiere a una palabra homérica que significa al mismo tiempo

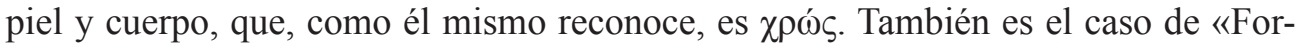
mas simples» (González Iglesias 2010a, pp.98-99) con las palabras de Marco Aurelio comparando las cosas del cuerpo con un río y las del alma con un sueño y una bruma, comparación que toma de Aur.II.17 y «Síndrome de la FNAC» (González Iglesias 2010a, p.124-125), donde nos recuerda unos versos de Píndaro, sobre cómo brilla un cuerpo juvenil sin fatigas «como un auriga de potencia y manos».

\subsection{UN ÁNGULO ME BASTA (2002)}

El título de este poemario nos remite directamente a una obra: la Epístola moral a Fabio, escrita por el capitán Andrés Fernández de Andrada. Concretamente, proviene de sus vv.127-129. Esta obra está, en su espíritu y en algunos de sus versos, en la línea de las epístolas horacianas, tanto por su género, la epístola poética, como por su contenido, la filosofía epicúrea, como señala el propio autor en el prólogo (González Iglesias 2010a, p.139-140). Dicha tradición pasa por el propio Epicuro, Virgilio y Horacio como hitos fundamentales. El adagio latino en que se basa el verso español, nisi in angulo cum libro, da cuenta de este ascetismo epicúreo. Este retiro del mundo está también en la etimología del verbo arceo del Carm.3.1 de Horacio: retirarse a un 
rincón propio. Nuevamente, horacianismo y epicureísmo están en los cimientos de la estética de González Iglesias, aunque en este caso es una influencia indirecta, a través de Fernández de Andrada.

El primero de los poemas que comentaremos es «Misántropo, ma non troppo» (González Iglesias 2010a, pp.144-145), que está precedido por unas palabras del emperador Marco Aurelio, en sus Meditaciones: «Que no te pase a ti con los misántropos lo mismo que a los hombres con los hombres», que reproduce la cita del em-

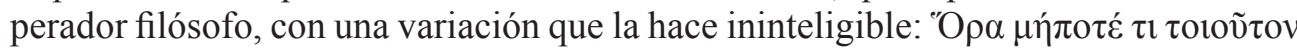

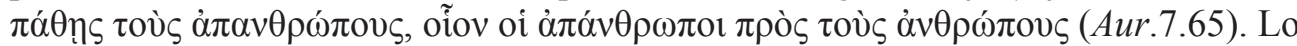
que nos dice Marco Aurelio es que no hay que tratar a los misántropos como ellos tratan a los demás hombres. El texto que reproduce la obra tendrá, seguramente, una errata, basada en la repetición de $\alpha \dot{\pi} \alpha v \theta \rho \omega ́ \pi$ ovৎ. En cualquier caso es muy elocuente cómo el poema, que empieza haciendo una apología misántropa, acaba haciendo caso al emperador y busca entre las personas a alguien que le merezca la pena, «un limpio de corazón», es decir, odia a los hombres en cuanto muchedumbre vulgar, pero no a todos.

«Tiene mi misma edad» (González Iglesias 2010a, pp.159-160) es un curioso poema dedicado a un minusválido psíquico que trabaja como jardinero. En él nuestro poeta recuerda un pasaje del Virgilio de las Geórgicas, en el momento en que éste se acuerda, sin nombrarlo, de Lucrecio, padre del epicureísmo en la poesía latina, a quien el Mantuano llamó afortunado por estar en contacto con la naturaleza: «Trata directamente con la tierra./ Dialoga con el sol de tú a tú./ Virgilio en la Geórgica segunda lo llamó afortunado», que remite a Geor.2.493: fortunatus et ille, deos qui nouit agrestis. Virgilio, en los dos versos previos, había alabado al poeta del De rerum natura, Geor.2.490-492: felix qui potuit rerum cognoscere causas/atque metus omnis et inexorabile fatum/ subiecit pedibus strepitumque Acherontis auari. Aquel ille, se refiere naturalmente a Lucrecio, cuya cercanía con la naturaleza atribuye González Iglesias al jardinero de su misma edad, objeto del poema. Con un sintagma el poeta consigue retrotraernos a Virgilio, en primera instancia, y, después, a Lucrecio, con lo cual el círculo epicúreo se cierra.

Además, los versos siguientes del poema de González Iglesias están también imbuidos del espíritu epicúreo, en cuanto alejamiento de los afanes y tedios cotidianos y a la exaltación de la vida rural, presente en la obra del griego Hesíodo, Trabajos $y$ días: «Yo aquí canto/ que desconoce la mordedura/ de la envidia. Que está/ lejos de los jerárquicos,/ ajeno/ a la soberbia de los sabios,/ como quiso Francisco/ de Asís», en clara alusión a los versos que siguen, a su vez, al anterior pasaje virgiliano, en Geor.2.495-496: non populi fasces, non purpura regum/ flexit et infidos agitans discordia fratres. El poema de González Iglesias parece estar compuesto con una estructura y calificativos paralelos al texto virgiliano, con los que además se recuerda implícitamente a Lucrecio y, probablemente, a Hesíodo. Además, González Iglesias adopta como paradigma de humildad a un cristiano, Francisco de Asís, tras una lista de poetas paganos, un reflejo de la fusión entre cristianismo y paganismo que se produjo en la Antigüedad tardía. 
«Nosotros no dormiremos en el lecho paterno» (González Iglesias 2010a, p.164) es un poema al que también hemos de prestar atención. Y es que el poema describe cómo el amor homosexual se aparta del heterosexual, el de sus antepasados. Es patente en versos como estos: «Al examen nocturno/ del amor acudimos a deshora y por libre./ En el camino somos un caballo y un potro». Estos caballos, que son los mismos amantes, le recuerdan a Homero: «Hablamos y lloramos igual que en la Ilíada/ los caballos de Aquiles. El amor nos transmuta», haciendo, naturalmente, referencia a Il.17.426-440, donde los caballos lloran la muerte de Patroclo, el compañero de armas y considerado, después de Homero, erómenos de Aquiles. La herencia griega y su abierta sexualidad le valen aquí al poeta de referencia cultural y de metáfora en lo que respecta a los amantes-caballos.

«Hermano» (González Iglesias 2010a, p.175), por su parte, es un curioso poema, que tiene como protagonista a uno de los 'héroes' de González Iglesias, un novicio deportista, cuya vida diaria relata el poeta: «En las horas futuras/ rezará, estudiará, traducirá latinos/y griegos sorprendentes». En este caso es la traducción de los clásicos la que constituye el objeto sobre el que versa el poema.

Más adelante, «Veinticuatro hexámetros» (González Iglesias 2010a, pp.176-178) es una extraña composición en la que lo clásico juega un papel muy importante. Según el poeta, estos veinticuatro hexámetros se refieren al número de los que tenían las inscripciones griegas, que en el poema están divididos en cinco apartados, entre los que se encuentran una petición a las musas para que lo busquen a las orillas del Escamandro y no entre los suyos o poemas que evocan un vaso griego del Hermitage: «Y sentir mi absoluta soledad cultural/ ahora, y la dulzura/ de aquello» o la Copa de Néstor, cuyo legado arcaico le atrae especialmente: «Anteriores a toda la tradición escrita/ buscamos la verdad en las formas más pobres/ de la escritura». Concluye estas composiciones con una declaración de principios, con la que se considera más un hombre de la Grecia clásica que de su tiempo: «¿Sería pedir mucho/ que mi obra completa,/ cuando pasen los siglos/ no llegue a rebasar los veinticuatro hexámetros/ de una inscripción antigua?».

El epicureísmo vuelve a ser parte de un poema, en este caso «Unconventional epicureans» (González Iglesias 2010a, p.179). En esta ocasión González Iglesias contradice al filósofo griego: «La puerta del jardín no la cerramos nunca/ porque nos apasiona la política». Y es que el fundador de la filosofía del jardín había mantenido una posición de rechazo de la actividad política, como recoge la número LVIII ${ }^{4}$

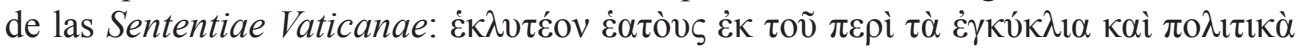
$\delta \varepsilon \sigma \mu \omega \tau \eta \rho i ́ o v$. Liberarse de la prisión de las rutinas y la política. Rechazo de lo político que González Iglesias no puede aceptar, ya que hay algunas causas en el espacio público que merecen su total adhesión.

Con el poema «En la sombra de la columna cabe el muchacho que lee» (González Iglesias 2010a, p.184) volvemos a encontrarnos con ese cultismo latino que es ángu-

\footnotetext{
${ }^{4}$ En este pasaje seguimos la ordenación y edición de los fragmentos de Epicuro de Bailey (1926, p.114).
} 
lo, junto con otros elementos: «Entre el Agamenón de Esquilo y Bomarzo de Mujica Lainez/ cualquiera de los libros de Occidente en sus/ manos./ El ángulo que forman la columna y su sombra/ tiene mucho que ver con el futuro». Aquí la lectura nos sitúa en tres lugares y momentos históricos que, por sí solos, corresponden a la transmisión de los clásicos desde Europa hacia América: Grecia, la Argentina del siglo XX y la Italia renacentista del siglo XVI, también presente en el argumento de la novela Bomarzo, y que ejerce, tanto en el poema como en la propia transmisión de los clásicos, de canalizador de los textos antiguos hacia los países americanos.

«Less is more» (González Iglesias 2010a, p.187) es otra muestra del epicureísmo del poeta. Si para Horacio no había nada por encima de ser un porcus de grege Epicuri en Ep.1.4.16, González Iglesias hace una declaración de intenciones sobre cuál es la actitud de un poeta del siglo XX y en qué consiste el ascetismo epicúreo contemporáneo:

Otra vez sufro el vértigo

de lo heterogéneo. El oasis

es una tentación para el asceta.

He comido en un centro comercial.

Sólo he comprado zumo de naranja

y las obras completas de Epicuro.

Algo que completa en otro poema, "Autorretrato como asceta inconsciente» (González Iglesias 2010a, pp.188-189):

Celebro la riqueza y la pobreza

porque son dones. Para leer a Horacio

un libro de bolsillo. Eso me basta.

Bibliofilia y tesoros, para otros.

Mis lujos se consiguen con dos euros.

Horacio, esta vez en su vertiente más estoica, aparece de nuevo en «Ya.com me ofrece megas ilimitados» (González Iglesias 2010a, pp.193), que, como se indica en su título, es una reflexión sobre la excesiva oferta de internet de una compañía telefónica, lo que le lleva a una crítica del consumismo y el bombardeo publicitario de nuestros tiempos. Y para ello se acuerda de cuando tradujo a Horacio: «Pero no yo, que alguna vez traduje/ a Horacio y sé que existen/ límites para todas las cosas», que nos remite, como paráfrasis, al est modus in rebus, sunt certi denique fines de Serm.1.1.106.

En el caso de «Momento perfecto patrocinado por Contrato 10 de Amena» (González Iglesias 2010a, pp.195-196) son los último versos, vv.870-871, del libro V de la Eneida los que le proporcionan el recurso para expresar ese retiro del mundo, que reproduce como paratexto de introducción al poema: $O$ nimium caelo et pelago confise sereno/ nudus in ignota, Palinure, iacebis harena y cita al final del poema: «Limpio absolutamente de rastros de pensamiento/ quedar desnudo en la ignorada 
arena». Algo que es muy paradójico, pues para elogiar este descanso y retiro se emplea el caso de Palinuro, el conductor de la nave de Eneas que murió en la travesía.

\subsection{SELVA DE FÁBULA (2010)}

Este poemario es un canto a la naturaleza y una invectiva contra aquellos que la urbanizan y la destruyen, con cuyas dos actitudes el poeta forma un díptico. En una primera parte, Selva (González Iglesias 2010a, pp.205-229), ensalza la naturaleza y sus bondades. Y en una segunda, Antitesis brutal a la Selva de fábula (González Iglesias 2010a, pp.233-247), se lamenta por el ataque a la naturaleza que el poeta presencia en su Salamanca natal.

En Selva nos encontramos con un hermoso canto dedicado a Salamanca, ciudad en la que ha nacido y vive el poeta, el imaginario clásico comienza por el ambiente bucólico, teocriteo y virgiliano en que el poeta ambienta su composición, como representación del tópico literario de la literatura europea del locus amoenus. Como señala Ponce (2014, pp.VII-VIII), el poema más extenso y cuidado de esta sección, Selva de fábula (González Iglesias 2010a, pp.205-207), debe mucho a la poesía de Pablo García Baena, por su juego de sonoridad, léxico latinizante, presencia de palabras esdrújulas o aliteraciones, en un metro más tradicional como es el endecasílabo, con los que consigue una plasticidad y solemnidad muy notables, de cuyo estilo presentamos una muestra a continuación:
Agua serena, horizontal, miniada por vesperal heraldo que trasvasa de un elemento a otro la hermosura, suma los campaniles y los álamos, selva de fábula, antes de la hora imprecisa en que logre la penumbra disolverla, y sus pájaros románicos, que al sol trinaban como arbóreas aves, duerman la noche al lado de los peces y las gárgolas góticas se ahoguen gurgitando el argén inagotable.

Será en la segunda parte donde el imaginario clásico tenga más presencia, ya que, de hecho, una sección de cuatro poemas lleva el sugerente título de «Minoría virgiliana» (González Iglesias 2010a, pp.235-240), aunque no se nos puede escapar que este elogio de la naturaleza per se es ya un guiño a las letras clásicas, precursoras de la estética del locus amoenus. En ellos se entremezcla el ambiente clásico de elogio a la naturaleza con un ataque a las invasiones medioambientales de la modernidad, tales como excavadoras, urbanización de espacios naturales o talas de bosques.

En Antitesis brutal a la Selva de fábula se produce el paso de la alabanza a la naturaleza, que ha ocupado la sección anterior, a un ataque a los que la destruyen y 
un lamento por el poco cuidado que recibe. Dentro de esta segunda parte hay cuatro poemas, los de «Minoría virgiliana», que desde su título se deben a los antiguos. El primero de ellos (González Iglesias 2010a, pp.235-236) comienza con una doble referencia, desengañada, a Salicio y Nemoroso, protagonistas de la Égloga I de Garcilaso de la Vega, heredero español de la tradición bucólica latina, y a Alexis, el amor trágico de Corydon, cuya relación relata Virgilio en Ec.2:

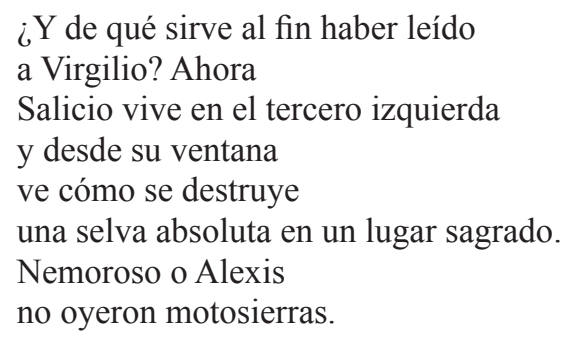

En el tercer poema (González Iglesias 2010a, p.239) de esta «Minoría virgiliana» el poeta se acuerda de Horacio: «He recordado una de las odas de Horacio/ -el pobre pez a quien el bloque arredra-», refiriéndose a Carm.3.1.33-34: contracta pisces aequora sentiunt/ iactis in altum molibus; huc frequens/ caementa demitit redemptor. En otro de los poemas de esta obra, «Nuestro amazonas mínimo», leemos un deseo del poeta, acordándose de Horacio en Epod.2 y Fray Luis de León en su «Oda a la vida retirada», obviando, naturalmente, la fuerte ironía de los últimos cuatro versos del epodo horaciano:

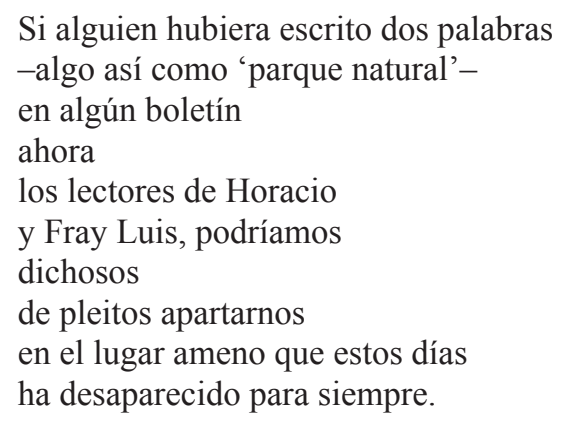

\subsection{OLÍMPICAS (2004)}

Esta obra la integran un conjunto de poemas de loa al deporte y al espíritu olímpico, tan caros a nuestro poeta. Allí se recogen algunos de los poemas previamente escritos con esta temática, además de otros inéditos, coincidiendo con la celebración de los Juegos Olímpicos de Atenas, precisamente, de 2004. Temáticamente, por tanto, es una obra heredera de Píndaro, fundamentalmente, aunque los atletas y las situaciones sean los modernos. De esta forma, vamos a encontrarnos con algunas citas de 
autores griegos y una nueva olímpica, al modo de la primera que hemos comentado al inicio de esta sección, en la que se ve más claramente esta influencia de la lírica pindárica en nuestro poeta salmantino.

Naturalmente, podemos rastrear el influjo de Píndaro en toda la obra y, de algún modo, en su misma concepción. La propia denominación Olímpicas, en cuanto cantos en homenaje a los atletas y celebración de la victoria, es por sí misma totalmente pindárica. En las líneas siguientes vamos a hacer una selección de aquéllas en las que observemos una deuda o mención del poeta a escritores y elementos clásicos, reelaborados, pero hemos de señalar que esta herencia se encuentra en todo el poemario antes de analizar nuestra selección.

El primer poema de esta obra que debemos comentar es «Contra la derrota» (González Iglesias 2010a, p.255). Supone un alegato del poeta contra el espíritu derrotista, frente al cual nos propone «un rayo de luz clásica sobre todas las cosas», es decir, el clasicismo como cura contra la decadencia cotidiana. Este verso que hemos citado, lo toma Ponce (2014) como título para su trabajo sobre González Iglesias.

«Contemplación del voley playa» (González Iglesias 2010a, pp.256-257) versa sobre una competición de este deporte con grouppies y DJ incluidos, donde el imaginario clásico se deja sentir en dos elementos fundamentales: en primer lugar, el Torso de Belvedere, que el estudioso Johann Joachim Winckelmann comparó con un roble y que a González Iglesias se le queda corto como término de comparación, por lo que toma la arena de este deporte para dicha comparación.

En segundo lugar, en este mismo poema nos encontramos con una referencia al Platón de Parm.138b-d, donde se refiere a la polémica de Sócrates con Aristóteles en torno al movimiento de lo uno, a raíz del movimiento de la arena por la actividad del deporte: «La arena, que propicia el pensamiento abstracto./ Platón en el Parménides: lo que está en movimiento/ se dirige al reposo. El podio. Dos perfiles».

«Tienen la plenitud de los adultos» (González Iglesias 2010a, pp.258-259) es un caso especial en el género olímpico. La concepción de los juegos modernos como una «pobre traducción de lo antiguo» cierra el poema, con un deseo perduración de las glorias atléticas más allá de la muerte, en el momento en el que los atletas reciben los honores de las autoridades:

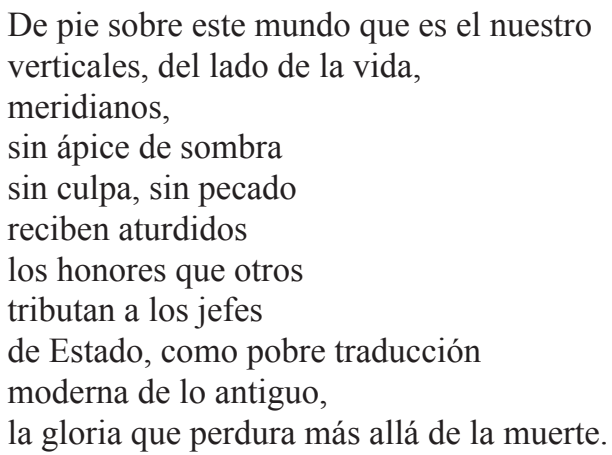


La «Olímpica tercera» (González Iglesias 2010a, pp.265-266), dedicada en este caso al atleta olímpico español David Cal es el majestuoso cierre a la serie de poemas que alaban a los atletas, y que, en realidad, están presentes en la obra de González Iglesias desde la primera página, como hemos visto. Este poema es una laudatio al atleta por su esfuerzo, constancia y atributos físicos. Un epinicio pindárico, en el que lo antiguo (Grecia, el olivo) y lo moderno (su música $m p 3$, internet, el piercing), a través de una victoria deportiva, se unen. En palabras de Cristóbal (2013, p.243): «El equilibrio entre el modelo antiguo y el dato contemporáneo -como la armónica conjunción del olivo y el chándal- es uno de los varios méritos de esta obra, que nos trae de la mano al grandioso Píndaro, libre de toda arqueología»:

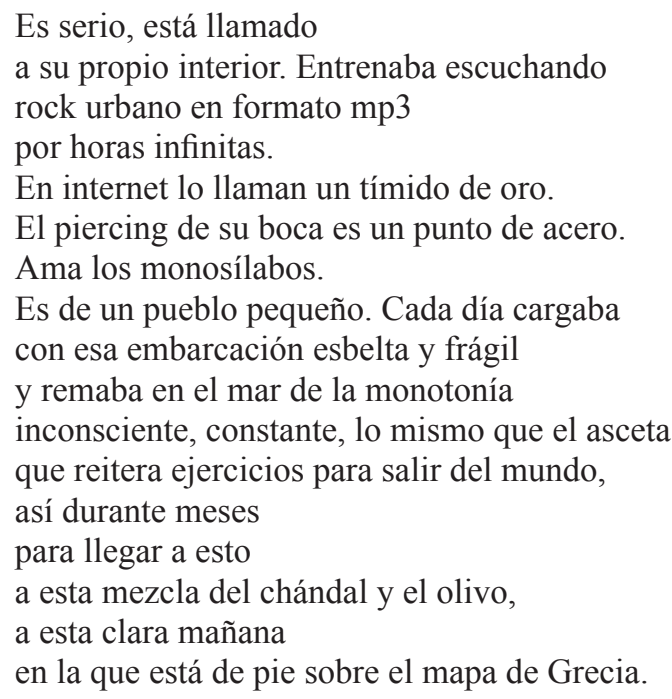

\subsection{EROS ES MÁS (2007)}

El título de este poemario se lo debe González Iglesias, como él mismo reconoce, a Aníbal Núñez, pues fue una respuesta que éste le dio en una entrevista, como nos relata en su prólogo (González Iglesias 2010a, pp.273-274). A continuación comenzaremos nuestro análisis con dos ejemplos en los que un elemento central del poema es la cita que le sugiere al autor nuevas concreciones de algunas máximas antiguas.

El primero es «Teoría de la fiesta» (González Iglesias 2010a, pp.278-279). En él

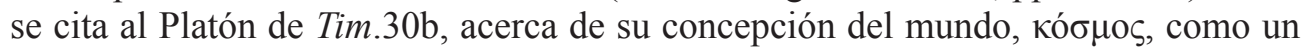
animal, a partir de lo cual González Iglesias compara el universo y la fiesta por su carácter único: «Platón dice que el cosmos es un gran animal./ Extraterritorial, así es la fiesta». El segundo poema en el que existe ese mismo recurso a la cita es «You light up my life» (González Iglesias 2010a, p.280), donde es el otro gran filósofo griego, Aristóteles, el que proporciona al autor una fórmula con la que construir su poema: «Aristóteles dice: un cuerpo bello/ debe ser percibido en su totalidad. Así te 
vi llegar esta mañana». Después nos contará cómo conoció a un joven, corriendo, y cómo se amaron después. Este poema también nos proporciona un nuevo ejemplo de convivencia de elementos de la literatura antigua (la cita de Aristóteles) y modernos (el título del poema hace referencia a una canción de Debby Boome).

«El tiempo engendra décadas» (González Iglesias 2010a, p.288) es una reflexión sobre la desproporción cronológica de las décadas como medida de tiempo para la historia y para la propia vida. En esta reflexión dicha medida de tiempo le recuerda a nuestro poeta a Tito Livio y su $A b$ urbe condita, ordenada precisamente en décadas, a pesar de que dicha estructura es algo discutido:

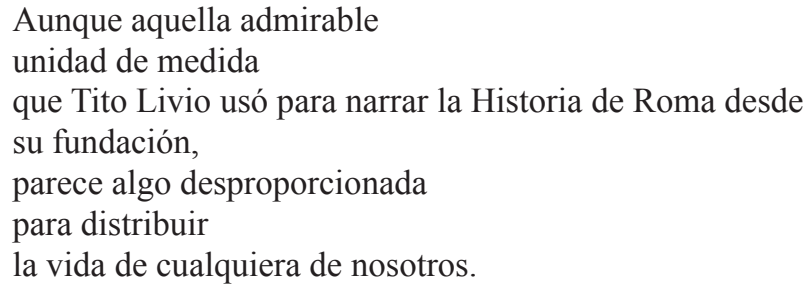

«Ultimus romanorum» (González Iglesias 2010a, p.295) también presenta un uso peculiar de un autor romano. En este caso, será San Agustín, un autor menos mencionado en su poesía. Todo el poema es una continua referencia a un discurso del obispo de Hipona que Robbie Williams, el cantante británico, introdujo en la letra de una de sus canciones. Una reflexión sobre la paradoja de que una plegaria a Dios de uno de los padres de la Iglesia Católica en plena decadencia del Imperio Romano, cuando tenía sólo 19 años, sea para pedirle que retrase su deseo de castidad. Un pecado de juventud, sin duda. La cita corresponde al recuerdo de la plegaria hecha por el obispo de Hipona, narrada en Conf.8.7, donde le pide a Dios castidad, pero más adelante. Antes, San Agustín ha narrado, curiosamente, cómo decidió iniciarse en la filosofía a raíz de la lectura del perdido Hortensio de Cicerón. Lo antiguo y lo inmediatamente contemporáneo, que aquí es, precisamente, transmisor de las palabras de los antiguos, unidos en un hermoso poema:
Ahora que también algo se termina
Robbie Williams dirige su micrófono hacia la multitud, que sin saberlo repite la plegaria de aquel joven romano apasionado y la propaga en videoclips y radios y en ipods. La más humana de las oraciones: da mihi castitatem, continentiam, sed noli modo. Oh Lord, make me pure - but not yet. Dame la castidad, la continencia. Hazme puro, Señor, pero no todavía. 
«¿Destinados al olvido?» (González Iglesias 2010a, pp.298-299) retoma el símil entre los hombres y las hojas, que hemos visto con «La canción del verano suena más que la Eneida» en las pp. 346-347. En este caso, el poeta está paseando por un parque, tras haber escuchado al escritor Álvaro Mutis una declaración pesimista de cómo los hombres están destinados a que nadie los recuerde. Allí encuentra un banco, con una inscripción en bronce, recordando a un joven fallecido a los 23 años, lo cual le recuerda el verso homérico:

In loving memory

En memoria de Justin A. Colonna

Son, brother \& friend

Feb, 16, 1976-Dec, 8, 1999

Leo tu claro nombre de italiano

patricio en este extremo de occidente,

mientras octubre se concreta en húmedas

hojas caídas sobre el banco donde

se habrán sentado tantos estudiantes.

Me viene al corazón el verso homérico

que compara a los hombres con las hojas.

Esto ni consuela ni le basta al poeta, que concluye su poema con estos versos, que son más bien un intento de rebelarse contra el aforismo homérico:

Por si acaso, escribimos, por si es cierto.

Por si el olvido fuera un episodio

provisional en nuestro largo viaje.

En medio de esta lluvia quién sabría

si somos destinados al olvido.

Tengo en cuenta el amor, el bronce, el breve

número de tus años y comprendo

que a mí, que no sé nada de tus días,

me corresponde ahora recordarte.

Entre las últimas composiciones de esta obra hay varios poemas que tienen como objeto el homenaje, la laudatio, sea hacia emperadores romanos o hacia la maestra del poeta en la Universidad de Salamanca. El primero, «Correspondencia» (González Iglesias 2010a, p.300) se lo sugiere al poeta una edición de las Meditaciones de Marco Aurelio, seguidas de la correspondencia del emperador con Frontón, su maestro. En él compara las fórmulas con las que encabezan sus cartas cada uno, con lo que el latín vuelve a ser un recurso literario, en este caso, para señalar el sobrio respeto de un discípulo, emperador a la sazón, a su maestro: «Varias cartas/ cruzadas entre el príncipe/ y el profesor, que siempre/ se dirige a su alumno/ respetuosamente:/ Domino Antonino Augusto./ En sus respuestas, el Emperador/ es aún más sencillo./ Sólo escribe:/ Magistro». Un nuevo ejemplo de uso literario del latín.

En «El reinado de Adriano» (González Iglesias 2010a, pp.307-308) encontramos como protagonista a otro de los grandes emperadores romanos. Con él, nuestro 
poeta salmantino recuerda con nostalgia aquella época, que le es más cercana que la suya propia. Tal vez sea la imagen que nos ha transmitido Marguerite Yourcenar en sus Memorias de Adriano, a las que el propio poeta se siente muy cercano, la que motive el poema. Su filohelenismo, su saeculum aureum junto a Antínoo y su pacifismo están, a buen seguro, detrás de esta simpatía que el poeta, en su doble condición de latinista y admirador confeso de Yourcenar, profesa en estos versos: «Percibo /aquello como patria,/ como época propia,/ porque intuyo que entonces no tendría/ la sensación de exilio/ creciente que despierta/ en mí la época que me ha tocado»».

Por último, en «Aikido» (González Iglesias 2010a, p.304) leemos un homenaje del poeta a su maestra en Salamanca, Carmen Codoñer. En él le agradece los conocimientos que le ha transmitido y recuerda sus años de estudiante, en los que la traducción, como no podía ser menos para un filólogo clásico, tiene un lugar privilegiado: «Los juegos, los poemas,/ las tardes traduciendo,/ palabra por palabra,/ las tragedias, el cruento/ latín de historiadores». Y termina con la fórmula con la que se saludan discípulo y maestro en el aikido: «Gracias por enseñarme».

\section{CONCLUSIONES}

La poesía de González Iglesias, como hemos tenido ocasión de ver en los párrafos anteriores, comparte algunas de las líneas generales de sus contemporáneos: el llamado neoculturalismo, la irrupción en sus versos del lenguaje de la publicidad, la sociedad de masas o la cultura pop. De hecho, la apuesta por el imaginario clásico no es exclusiva de él, ni siquiera de los llamados 'novísimos', la generación anterior, sino que son muchos los poetas españoles contemporáneos que han optado por el clasicismo grecolatino para dar forma y contenido a sus poemas, como nos han mostrado Conde Parrado y García Rodríguez (2005) con su Orfeo XXI.

Sin embargo, no podemos integrar sin más a González Iglesias en una estética literaria, con la que tiene, ciertamente, elementos comunes. Nuestro poeta, además de dar un nuevo contexto a temas clásicos, ha retomado algunas formas poéticas que son minoritarias en la tradición poética española. A saber: la oda epinicial pindárica, con escasos precedentes en nuestras letras y protagonizada ahora por nuestros modernos atletas, el epilio amoroso y el himno, ya no dedicado a la divinidad sino a jóvenes hermosos. Asimismo, retoma el catálogo, recurso compositivo épico, que desde Homero y la épica clásica, a través de Walt Whitman, ha llegado a ser un género poético en sí mismo y una de las formas más efectivas de explicar la complejidad de la ciudad moderna.

Todo ello demuestra que los antiguos no han terminado de transmitirnos todo su mensaje y que sus versos guardan aún 'virtualidades ocultas', en terminología de Jauss (1976, pp.176-177), que están por aflorar, a través de la actualización de su significado que produce el creador literario contemporáneo en su lectura de los textos antiguos grecolatinos. 


\section{REFERENCIAS BIBLIOGRÁFICAS}

\section{A) FUENTES}

BAILey, C. (1926), Epicurus. The extant remains, Oxford, Oxford Clarendon Press.

Castellet, J.M. (1970), Nueve poetas novísimos españoles, Barcelona, Barral Editores.

Conde Parrado, P. - García Rodríguez, J. (eds.) (2005), Orfeo XXI. Poesía española contemporánea y tradición clásica, Gijón, Libros del Pexe.

GonzÁlez Iglesias, J.A. (1993), Ovidio. Amores. Arte de amar, Madrid, Cátedra.

GonzÁlez Iglesias, J.A. y Fernández Corte, J.C. (2006), Catulo. Poesías, Madrid, Cátedra.

GonzÁlez Iglesias, J.A. (2010a), Del lado del amor. Poesía reunida (1994-2009), Madrid, Visor.

GonzÁlez Iglesias, J.A. (2012a), Horacio. Arte poética, Madrid, Cátedra.

GonzÁlez Iglesias, J.A. (2012b), Ceci est mon corps, Belval, Circé.

GonzÁlez Iglesias, J.A. (2014), Eros is more, Farmington, Alice James Books.

SÁnchez-MesA, D. (2007), Cambio de siglo. Antología de poesía española 1990-2007, Madrid, Hiperión.

VillenA, L.A. DE (2010), La inteligencia y el hacha. Un panorama de la generación de 2000, Madrid, Visor.

\section{B) ESTUDIOS}

BÁdenas, P. - Bernabé, A. (2002), «Introducción general», Píndaro. Epinicios, Madrid, Akal. Borges, J.L. (2011), Miscelánea, Madrid, Debolsillo.

CRISTÓBAL, V. (1992), «Una comparación de clásico abolengo y larga fortuna», $C F C(L) 2$, 155-187.

CRistóBAL, V. (1997), «Virgilio en Jorge Guillén», CFC (L) 13, 37-47.

CRistóBAL, V. (2009), «La tradición clásica: una constante en la historia de Occidente», Nueva revista, recurso on-line: [http://www.nuevarevista.net/articulos/tradicion-clasicauna-constante-en-la-historia-de-occidente]. Fecha de consulta: 18-11-2014.

CRISTÓBAL, V. (2013), «Clasicismo grecolatino en la poesía española de los últimos tiempos», en GonzÁlez AlcÁzAR, F. et al., Literatura, pasión sagrada. Homenaje al profesor Antonio García Berrio, Madrid, UCM, pp.237-256.

FERnÁndez López, J. (2005), «Orfeo ya no vive aquí», en Conde PARRAdo, P. - GARCía RoDRíguez, J. (eds.), Orfeo XXI. Poesía española contemporánea y tradición clásica, Gijón, Libros del Pexe.

García Jurado, F. (2006), El arte de leer, Madrid, Liceus.

Genette, J. (1989), Palimpsestos: la literatura en segundo grado, Madrid, Taurus.

GONZÁLEZ IgLESIAS, J.A. (1994), «Exegi/ monumentum/ aere/ perennius. Una lectura desde la estética postmoderna», en FERnÁndEz CORTE, J.C. - CORTÉS TOVAR, R. (eds.), Bimilenario de Horacio, Salamanca, Editorial Universidad de Salamanca, pp.385- 397.

González Iglesias, J.A. (2010b), Poética y poesía. Bajo el signo de Horacio, Madrid, Fundación Juan March. 
GonzÁlez Iglesias, J.A. (2010c), «Carpe diem: desde Epicuro hasta la Coca-Cola», en AleMANY Ferrer, R. - Chico Rico, F. (eds.), XVIII Simposio de la SELGYC, pp.253- 264.

JAUSS, H. R. (1976), La historia de la literatura como provocación, Barcelona, Península.

LAGunA, G. (1999), «En tierra, en humo, en polvo, en sombra, en nada: historia de un tópico literario», Anuario de Estudios Filológicos 22, 197-213.

Olmo Iturriarte, A. Del - Díaz de Castro, F. (eds.) (2011), Versos robados. Tradición Clásica e intertextualidad en la lírica posmoderna peninsular, Madrid, Renacimiento.

Ponce CÁrdenas, J. (2014), «Un rayo de luz clásica sobre todas las cosas», Lectura y signo 9, III-XII.

RiQuer, M. DE - Valverde, J.M. (2010), Historia de la literatura universal. Tomo II: Del barroco hasta nuestros días, Madrid, Gredos.

Rodríguez, J. (2007), «Ovidio con iPod», El País, 16 de marzo de 2007, recurso on-line: [http://elpais.com/diario/2007/03/16/cultura/1173999602_850215.html]. Fecha de consulta: 18-XI-2015.

Rodríguez Herrera, G. (2008), La Tradición Clásica en los poetas canarios del Grupo de los Noventa, Madrid, Aduana Vieja.

Ruano, C. (2014), «Entre visillos: Juan Antonio González Iglesias», Salamanca al día, recurso online: [http://salamancartvaldia.es/not/53723/juan-antonio-gonzalez-iglesias-ldquo-un-siglo-entero-de-materialismo-despiadado-ha-dejado-a-la-gente-bajo-minimosrdquo-/]. Fecha de consulta: 24-11-2014.

Villena, L.A. De (2007), «Entre el gimnasio y la biblioteca», El País, 27 de enero 2007, recurso on-line: [http://elpais.com/diario/2007/01/27/babelia/1169859023_850215.html]. Fecha de consulta: 18-11-2015. 